\title{
A Novel Nervous System $\beta$ Subunit that Downregulates Human Large Conductance Calcium-Dependent Potassium Channels
}

\author{
Thomas M. Weiger, ${ }^{1,3}$ Mats H. Holmqvist, ${ }^{1}$ Irwin B. Levitan,, ${ }^{1}$ Frederick T. Clark, ${ }^{2}$ Scott Sprague, ${ }^{2}$ \\ Wann-Jeng Huang, ${ }^{2}$ Pei Ge, ${ }^{2}$ Chichung Wang, ${ }^{2}$ Deborah Lawson, ${ }^{2}$ Mark E. Jurman, ${ }^{2}$ \\ M. Alexandra Glucksmann, ${ }^{2}$ Inmaculada Silos-Santiago, ${ }^{2}$ Peter S. DiStefano, ${ }^{2}$ and Rory Curtis ${ }^{2}$ \\ ${ }^{1}$ Department of Biochemistry and Volen Center for Complex Systems, Brandeis University, Waltham, Massachusetts \\ 02454, 2Millennium Pharmaceuticals, Cambridge, Massachusetts 02139, and ${ }^{3}$ Department of Molecular Neurobiology \\ and Cell Physiology, Institute of Zoology, University of Salzburg, A-5020 Salzburg, Austria
}

The pore-forming $\alpha$ subunits of many ion channels are associated with auxiliary subunits that influence channel expression, targeting, and function. Several different auxiliary $(\beta)$ subunits for large conductance calcium-dependent potassium channels of the Slowpoke family have been reported, but none of these $\beta$ subunits is expressed extensively in the nervous system. We describe here the cloning and functional characterization of a novel Slowpoke $\beta 4$ auxiliary subunit in human and mouse, which exhibits only limited sequence homology with other $\beta$ subunits. This $\beta 4$ subunit coimmunoprecipitates with human and mouse Slowpoke. $\beta 4$ is expressed highly in human and monkey brain in a pattern that overlaps strikingly with Slowpoke $\alpha$ subunit, but in contrast to other Slowpoke $\beta$ subunits, it is expressed little (if at all) outside the nervous system. Also in contrast to other $\beta$ subunits, $\beta 4$ downregulates Slowpoke channel activity by shifting its activation range to more depolarized voltages and slowing its activation kinetics. $\beta 4$ may be important for the critical roles played by Slowpoke channels in the regulation of neuronal excitability and neurotransmitter release.

Key words: potassium channel; $\beta$ subunit; in situ hybridization; Slowpoke; maxi K; calcium-dependent potassium channel
Large conductance calcium-dependent potassium $\left(\mathrm{K}_{\mathrm{Ca}}\right.$ or maxi $\mathrm{K})$ channels are ubiquitous in nerve, muscle, and other cell types (Kaczorowski et al., 1996; Vergara et al., 1998). They play a particularly important role in neuronal signaling, because they respond to both the intracellular calcium concentration and the membrane potential. Neuronal $\mathrm{K}_{\mathrm{Ca}}$ channels are enriched in axons and synaptic terminals (Knaus et al., 1996). They not only contribute to action potential repolarization and the control of firing frequency but also are critical for the regulation of neurotransmitter release (Gho and Ganetzky, 1992; Robitaille and Charlton, 1992; Robitaille et al., 1993; Bielefeldt and Jackson, 1994). These channels are key integrators of neuronal activity, because they provide a link between intracellular biochemical messenger systems and the electrical properties of the plasma membrane.

The pore-forming $\alpha$ subunits of $\mathrm{K}_{\mathrm{Ca}}$ channels are encoded by the Slowpoke genes that have been described in many organisms (Adelman et al., 1992; Butler et al., 1993; Dworetzky et al., 1994; Pallanck and Ganetzky, 1994; Tseng-Crank et al., 1994). Although these $\alpha$ subunits can form functional channels when they are expressed alone in heterologous host cells, they may often be

\footnotetext{
Received Jan. 24, 2000; revised March 1, 2000; accepted March 8, 2000.

This work was supported in part by a grant to I.B.L from the National Institutes of Health. We thank Dr. F. Benes (Harvard Brain Tissue Resource Center) for providing the human brain samples, Larry Salkoff and Steve Dworetzky for the mSlo and hSlo 1 subunit cDNAs, and Tom Grace at Millennium Pharmaceuticals for assistance with some of the figures.

Correspondence should be addressed to Irwin B. Levitan's present address: Department of Neuroscience, University of Pennsylvania School of Medicine, 215 Stemmler Hall, 3450 Hamilton Walk, Philadelphia, PA 19104-6074. E-mail: levitani@mail.med.upenn.edu.

Dr. Weiger's present address: Department of Neuroscience, University of Pennsylvania School of Medicine, 218 Stemmler Hall, Philadelphia, PA 19104.

Dr. Holmqvist's present address: Millennium Pharmaceuticals, 75 Sidney Street, Cambridge, MA 02139.

Copyright (C) 2000 Society for Neuroscience $\quad 0270-6474 / 00 / 203563-08 \$ 15.00 / 0$
}

associated with auxiliary subunits in native tissues. For example, $\mathrm{K}_{\mathrm{Ca}}$ channels purified from smooth muscle consist of the $\alpha$ subunit together with a $20-25 \mathrm{kDa}$ membrane protein that has been termed a $\beta$ subunit (Garcia-Calvo et al., 1994; Hanner et al., 1998). Voltage-dependent sodium, calcium, and potassium channels also copurify with $\beta$ and other subunits that are important for channel expression, membrane targeting, and modulation (Isom et al., 1994; Rettig et al., 1994; Dunlap et al., 1995; Rhodes et al., 1995; Trimmer, 1998).

Slowpoke channel $\beta$ subunits have been cloned from several sources. When the first-described $\beta 1$ subunit (Knaus et al., 1994) is coexpressed with the $\alpha$ subunit, it can modulate Slowpoke channel activity, influence channel modulation by protein kinases, and alter toxin binding to the channel (McManus et al., 1995; Dworetzky et al., 1996; Tseng-Crank et al., 1996). This $\beta 1$ subunit also binds estradiol and may mediate the activation of $\mathrm{K}_{\mathrm{Ca}}$ current by the hormone in vascular smooth muscle (Valverde et al., 1999). A related protein has been cloned from quail (Oberst et al., 1997), but its functional properties have not yet been investigated. More recently, a protein that confers rapid inactivation on Slowpoke channels has been described. This protein, named $\beta 2$ by one group (Wallner et al., 1999) and $\beta 3$ by another (Xia et al., 1999), exhibits $\sim 45 \%$ identity with $\beta 1$, and the overall membrane topologies of $\beta 1$ and $\beta 2 / 3$ are identical, with two transmembrane regions separated by a large extracellular domain. $\beta 1$ is expressed prominently in peripheral tissues, including smooth muscle, but only to a very limited extent in brain (TsengCrank et al., 1996). $\beta 2 / 3$ is expressed in many tissues (Wallner et al., 1999; Xia et al., 1999), and it is likely responsible for the rapid inactivation of $\mathrm{K}_{\mathrm{Ca}}$ current in adrenal chromaffin cells (Solaro and Lingle, 1992; Solaro et al., 1995) and some neurons (Hicks and Marrion, 1998). 
a
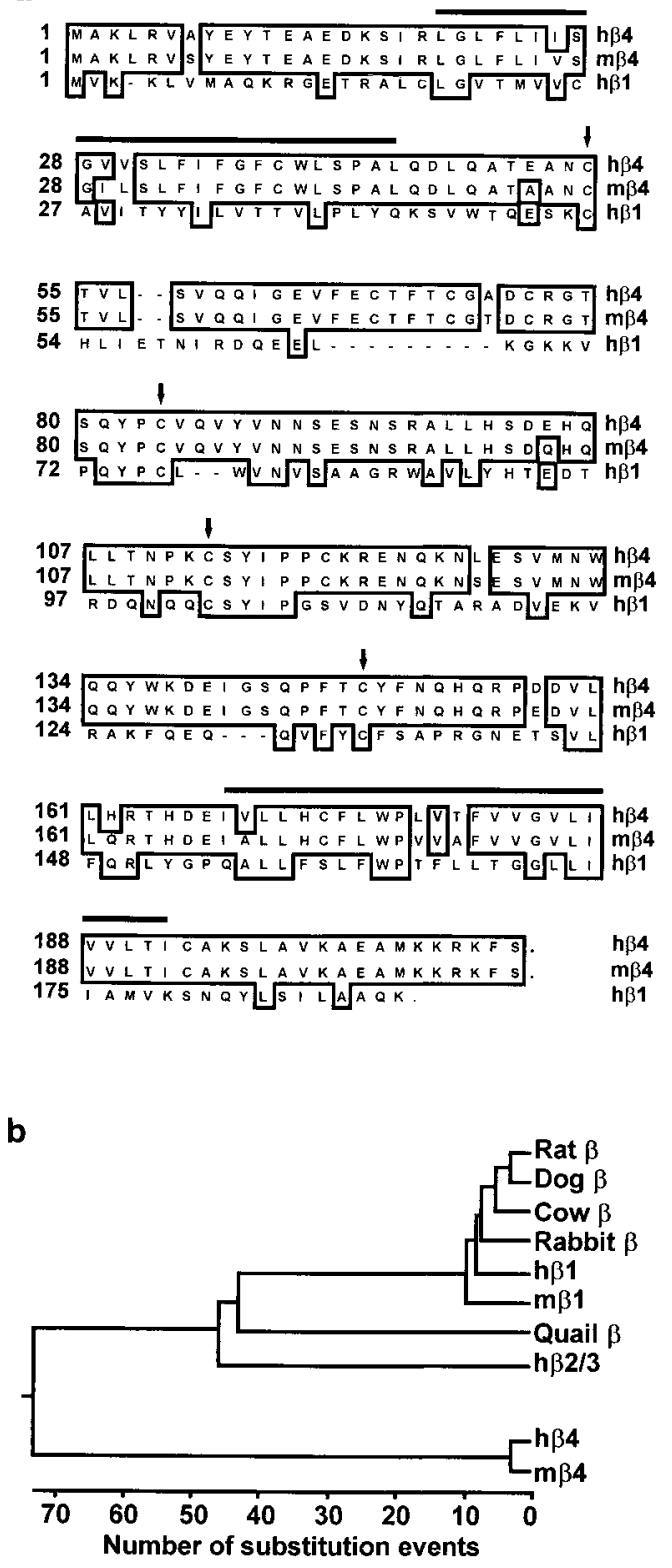

Figure 1. Sequence analysis of Slowpoke $\beta$ subunits. $a$, Amino acid sequences of $\mathrm{h} \beta 4$ (GenBank accession number AF215891), m $\beta 4$ (GenBank accession number AF215892), and $\mathrm{h} \beta 1$ (GenBank accession number U38907) are aligned by the clustal method. Amino acids conserved in the $\beta$ subunits are boxed. The horizontal bars indicate the two predicted membrane-spanning regions in $\beta 4$, and conserved cysteine residues in the predicted extracellular loops are marked by arrows. $b$, Phylogenetic tree of Slowpoke $\beta$ subunits cloned to date. The length of each pair of branches represents the evolutionary distance between sequence pairs, as measured by the number of substitution events. The Slowpoke $\beta 4$ subunits described in this paper form a gene family distinct from other $\beta$ subunits, which fall into a separate and evolutionarily conserved family. The GenBank accession numbers for the previously cloned $\beta$ subunits used in this analysis are as follows: rat $\beta, 1718491 ; \operatorname{dog} \beta, 1127826$; $\operatorname{cow} \beta, 508846$; rabbit $\beta, 2662318$; $\mathrm{h} \beta 1, \mathrm{U} 38907 ; \mathrm{m} \beta 1,2347044 ;$ quail $\beta, \mathrm{U} 67865$; and $\mathrm{h} \beta 2 / 3, \mathrm{AF} 099137$.

The $\mathrm{K}_{\mathrm{Ca}}$ channels formed by coexpressing hSlo and $\mathrm{h} \beta 1$ are pharmacologically distinct from those present in brain, and a different $\beta$ subunit has been identified in brain membranes by biochemical approaches (Wanner et al., 1999). We describe here
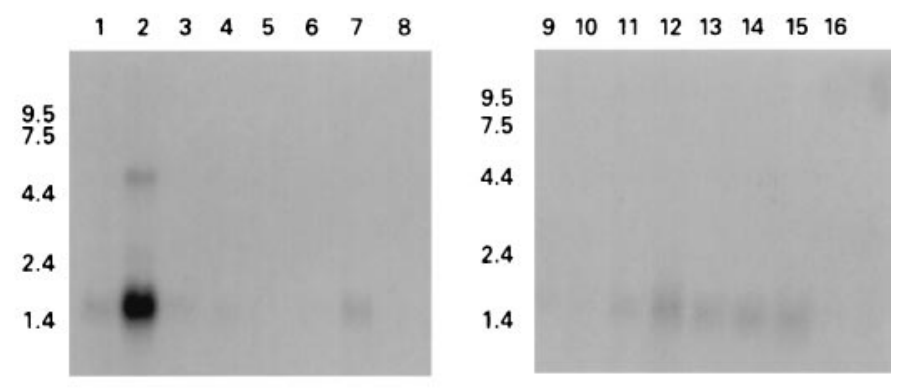

$\begin{array}{llllllll}17 & 18 & 19 & 20 & 21 & 22 & 23 & 24\end{array}$

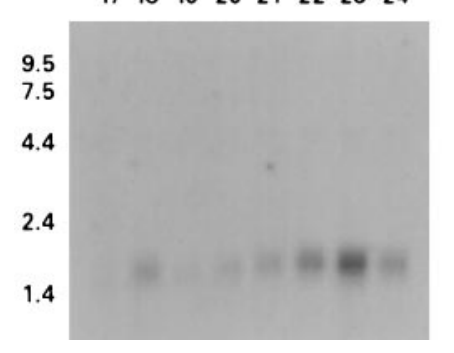

$\begin{array}{llllllll}25 & 26 & 27 & 28 & 29 & 30 & 31 & 32\end{array}$

Figure 2. Analysis of $\beta 4$ expression using human multiple tissue (top panels) and brain region (bottom panels) Northern blots. A predominant $1.6 \mathrm{~kb}$ band is detected in brain, particularly in cortical regions, and a minor $5 \mathrm{~kb}$ band is also seen in brain. Fainter signals can also be detected in peripheral tissues. Lanes: 1 , heart; 2, brain; 3, placenta; 4, lung; 5, liver; 6, skeletal muscle; 7, kidney, 8 , pancreas; 9, spleen; 10, thymus; 11 , prostate; 12 , testes; 13 , ovary; 14 , small intestine; 15 , colon; 16 , peripheral blood leukocyte; 17, cerebellum; 18, cerebral cortex; 19, medulla; 20, spinal cord; 21, occipital lobe; 22, frontal lobe; 23, temporal lobe; 24 , putamen; 25, amygdala; 26, caudate nucleus; 27, corpus callosum; 28, hippocampus; 29, whole brain; 30, substantia nigra; 31, subthalamic nuclei; 32, thalamus.

the cloning, expression pattern, and functional properties of a novel Slowpoke auxiliary subunit in human brain. This protein, which we call $\mathrm{h} \beta 4$, is only distantly related to the known Slowpoke auxiliary subunits. We also have cloned the mouse ortholog $\mathrm{m} \beta 4$. Under the conditions we have examined, the effects of $\beta 4$ on Slowpoke channel properties are diametrically opposite to those of $\beta 1$ and $\beta 2 / 3$ in that channel activity is downregulated by $\beta 4$. Slowpoke $\beta 4$ may contribute to the modulation of neuronal excitability and neurotransmitter release by Slowpoke family channels.

\section{MATERIALS AND METHODS}

Cloning and sequence analysis. $\mathrm{h} \beta 4$ was identified and cloned using the strategy described in Results (GenBank accession number AF215891). To clone a mouse homolog, a BLAST search of the mouse Expressed Sequence Tag (EST) database was performed using the human sequence as the input. One significant hit was obtained with GenBank accession number AI180680. This EST did not encode a full-length mouse homolog, but the sequence was used to design $3^{\prime}$ and $5^{\prime}$ rapid amplification of cDNA ends (RACE) primers. RACE reactions were performed with these primers using mouse brain cDNA (Clontech, Palo Alto, CA). A full open reading frame could be deduced from the cloned and sequenced RACE products (GenBank accession number AF215892). Two new primers were designed in the $3^{\prime}$ untranslated region after the stop codon and were used to obtain a full-length physical clone from mouse brain cDNA. This was cloned into pcR2.1(TOPO; Invitrogen, San Diego, $\mathrm{CA})$. The $\mathrm{h} \beta 4$ and $\mathrm{m} \beta 4$ clones were subcloned and epitope-tagged with a V5-His tag in the mammalian expression vector pcDNA3.1 V5-His (Invitrogen). They also were subcloned into the pIRES2-EGFP vector (Clontech), a bicistronic vector that allows coexpression of $\mathrm{h} \beta 4$ and green fluorescent protein (GFP) in the same cell. All constructs were sequenced throughout the full open reading frame (ABI Prism system; Brandeis University Sequencing Facility, Waltham, MA). No PCRinduced nucleotide change was observed in any of the RACE products or 

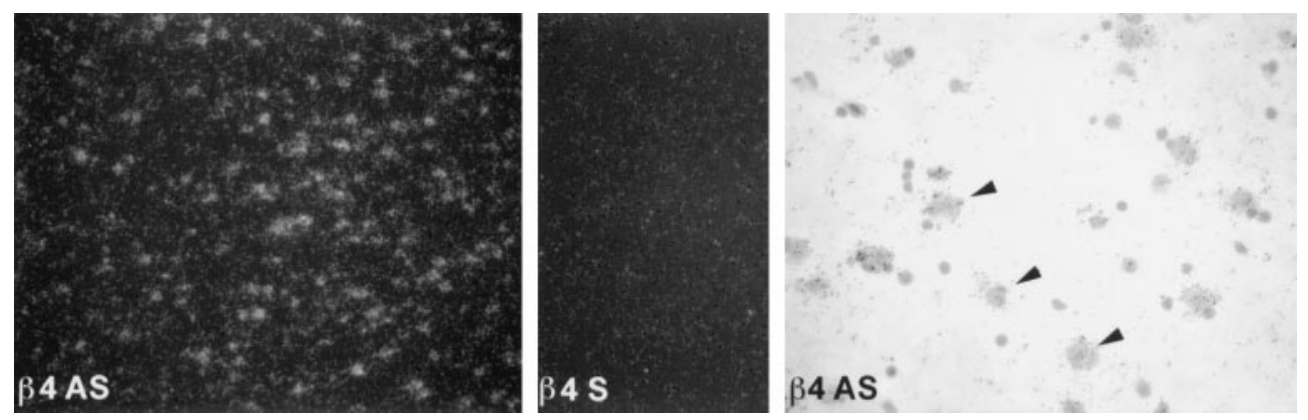

Figure 3. Expression of $\beta 4$ in human cortex. Emulsion autoradiograms of sections from human cortex, labeled with human $\beta 4$ antisense ( $\beta 4$ AS, left panel) and sense ( $\beta 4 S$, middle panel) probes, were viewed under dark-field illumination (10× magnification). The antisense probe shows $\beta 4$ expression throughout the cortical layers, whereas the sense probe shows only background. A bright-field image of the same tissue ( $\beta 4 A S$, right panel) shows $\beta 4$ expression (arrowheads) in cortical neurons $(40 \times$ magnification).

the cloned mammalian expression constructs. Amino acid alignments and phylogenetic tree calculations were done using DNAStar Inc. (Madison, WI) software. The phylogenetic analysis assumes a biological clock, represented by the distance between sequence pairs.

Tissue and brain region distribution. A PCR fragment from the $\mathrm{h} \beta 4$ clone was labeled with ${ }^{32} \mathrm{P}$ and used to probe human multiple tissue and brain region Northern blots (Clontech). In situ hybridization was performed with human cRNA probes corresponding to hSlo $\alpha$ subunit, $\mathrm{h} \beta 1$, $\mathrm{h} \beta 2 / 3$, and $\mathrm{h} \beta 4$, essentially as described previously (Stahl et al., 1999), using $12 \mu \mathrm{m}$ fresh-frozen sections prepared from cynomolgus monkey tissues and human brain (obtained from the Harvard Brain Tissue Resource Center, Belmont, MA). Human and monkey aorta and adrenal gland sections were used as positive controls for $\mathrm{h} \beta 1$ and $\mathrm{h} \beta 2 / 3$ probes, respectively.

Mammalian cell expression. Human embryonic kidney 293 (HEK 293)
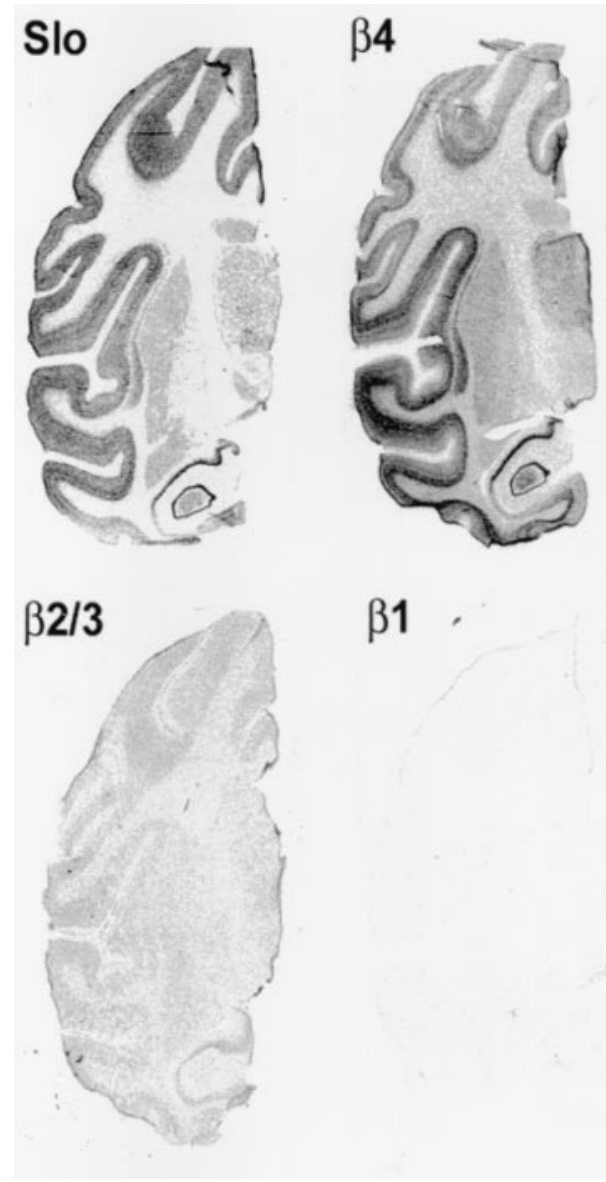

$\beta 1$

Figure 4. Expression of Slowpoke $\alpha$ and $\beta$ subunits in monkey brain. Film autoradiograms of monkey brain sections hybridized with antisense probes that detect mRNA encoding Slowpoke $\alpha$ subunit (Slo), $\beta 4, \beta 2 / 3$, and $\beta 1$. Note the overlapping expression of $\alpha$ subunit (Slo) and $\beta 4$ in multiple brain regions, with considerably lower levels of $\beta 2 / 3$ and little or no expression of $\beta 1$. cells were maintained in MEM supplemented with $10 \%$ fetal bovine serum (FBS) and 1\% penicillin-streptomycin (pen-strep). Chinese hamster ovary $(\mathrm{CHO})$ cells were cultured in Ham's F12 nutrient mixture plus $10 \%$ FBS and $1 \%$ pen-strep. Cells were seeded on poly-D-lysinecoated coverslips and transfected the next day with appropriate expression plasmids using Lipofectamine Plus (Life Technologies, Gaithersburg, MD) according to the manufacturer's guidelines.

Coimmunoprecipitation and Western blot. These experiments were done as described previously (Zhou et al., 1999). Epitope-tagged h $\beta 4$ or $\mathrm{m} \beta 4$ in pcDNA3.1 was expressed in HEK 293 cells, either alone or together with hSlo or mSlo ([kindly provided by Steve Dworetzky (Bristol-Myers Squibb, Wallingford, CT) and Larry Salkoff (Washington University, St. Louis, MO), respectively]). Forty-eight hours after transfection, the cells were lysed and incubated with antibody directed against mSlo or against the His epitope (Invitrogen). The mSlo antibody recognizes a region in the $\mathrm{C}$-terminal domain of both mSlo and hSlo $(\mathrm{H}$. Wen and I. B. Levitan, unpublished observations). The immune complexes were precipitated by incubation with protein A/G PLUS-Agarose beads (Santa Cruz Biotechnology, Santa Cruz, CA). Proteins in the lysates or immunoprecipitates (IPs) were separated on polyacrylamide gels and transferred to a nitrocellulose membrane. After blocking with 5\% nonfat milk in TBST (0.1\% Tween 20 in Tris-buffered saline), the blots were probed with primary antibodies directed either against mSlo or the V5 epitope. Horseradish peroxidase (HRP)-coupled anti-V5 (Invitrogen) was used as the primary antibody for $\mathrm{h} \beta 4 / \mathrm{m} \beta 4$ blots, so no secondary antibody was required. HRP-coupled donkey anti-rabbit IgG (Amersham Pharmacia Biotech, Arlington Heights, IL) was used as the secondary antibody for hSlo/mSlo blots. Membranes were washed with TBST, and protein was visualized with an enhanced chemiluminescence detection system (Amersham Pharmacia Biotech).

Electrophysiology. HEK 293 and CHO cells were used for recordings 1-3 d after transfection. Cells expressing GFP were identified by their green fluorescence, and all such green cells were found to exhibit current. Macroscopic currents were recorded from inside-out patches within several minutes of detaching the patch or in the whole-cell recording mode after the currents had stabilized. Solutions for inside-out patch recordings consisted of (in $\mathrm{mM}$ ): $150 \mathrm{KCl}, 10 \mathrm{HEPES}, 5 \mathrm{Na}-\mathrm{EGTA}$, and $0.5 \mathrm{MgCl}_{2}, \mathrm{pH} 7.2$ on both sides of the patch. Calcium was added to the intracellular side in an appropriate amount to give a final free calcium concentration of $0.3,1$, and $3 \mu \mathrm{M}$ as calculated with Equal software from Biosoft (Cambridge, UK). Solutions for whole-cell recordings were as follows: bath solution, $145 \mathrm{~mm} \mathrm{NaCl}, 5 \mathrm{mM} \mathrm{KCl}, 1 \mathrm{mM} \mathrm{MgCl}_{2}, 1 \mathrm{~mm}$ $\mathrm{CaCl}_{2}$, and $10 \mathrm{~mm}$ HEPES, pH 7.2; electrode solution, $150 \mathrm{mM} \mathrm{KCl}, 10$ $\mathrm{mM}$ HEPES, $5 \mathrm{~mm} \mathrm{Na}-E G T A, 0.5 \mathrm{~mm} \mathrm{MgCl}_{2}$, and $10 \mu \mathrm{M}$ free calcium, $\mathrm{pH}$ 7.2. All chemicals were from Sigma (St. Louis, MO) or Fisher Scientific (Houston, TX), except synthetic charybdotoxin, which was purchased from Research Biochemicals (Natick, MA). Experiments were controlled and recorded on-line with pClamp 7 software (Axon Instruments, Foster City, CA). Currents were amplified with an Axopatch 200A amplifier (Axon Instruments). Data were analyzed with pClamp7, filtered off-line at $1 \mathrm{kHz}$ and leak subtracted if necessary. For activation curves, cells were held at $-100 \mathrm{mV}$, and depolarizations in steps of $10 \mathrm{mV}$ were applied for $150 \mathrm{msec}$. The maximal conductance $\left(G_{\max }\right)$ was calculated from deactivating tail currents. For lower calcium concentrations, $G_{\max }$ was estimated from recordings done on the same patch at a higher calcium concentration. Conductance data were expressed as $G / G_{\max }$ and were fitted to the Boltzmann equation. All results are presented as mean \pm SEM, and statistical significance was assessed by ANOVA analysis with Bonferroni's multiple comparison post test. 
Figure 5. Analysis of Slowpoke $\alpha$ and $\beta$ subunit expression in different regions of monkey brain. Emulsion autoradiograms of monkey brain sections, labeled with antisense probes to detect Slowpoke $\alpha$ (Slo, top row), $\beta 4$ (second row), $\beta 2 / 3$ (third row), and $\beta 1$ (bottom row) subunits, were viewed under dark-field illumination. Slo and $\beta 4$ are expressed in cortex $(C T X)$, in the dentate gyrus (arrow) and CA3 (arrowhead) regions of hippocampus $(H I P)$, and in thalamus (THL). $\beta 2 / 3$ is expressed at lower levels and in apparently fewer cells in cortex and hippocampus and is not detected in thalamus. $\beta 1$ expression is not detectable in any of these areas $(10 \times$ magnification).
Slo
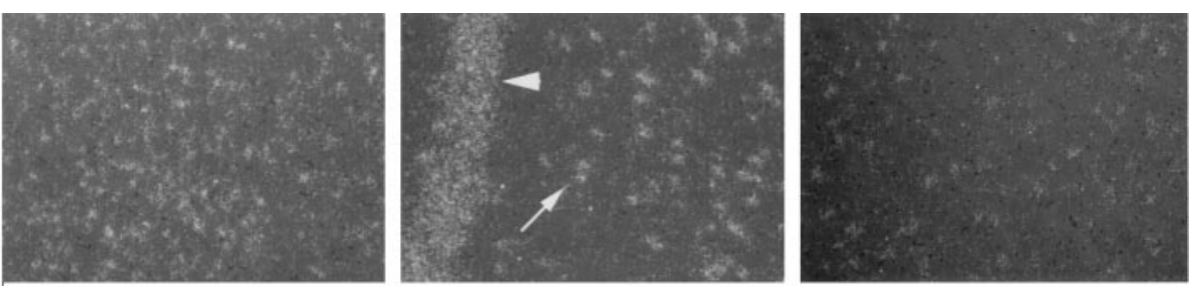

$\beta 4$
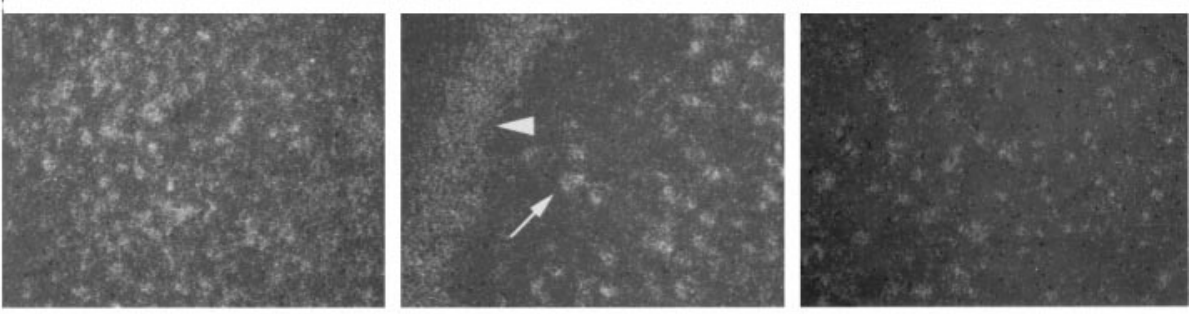

$\beta 2 / 3$
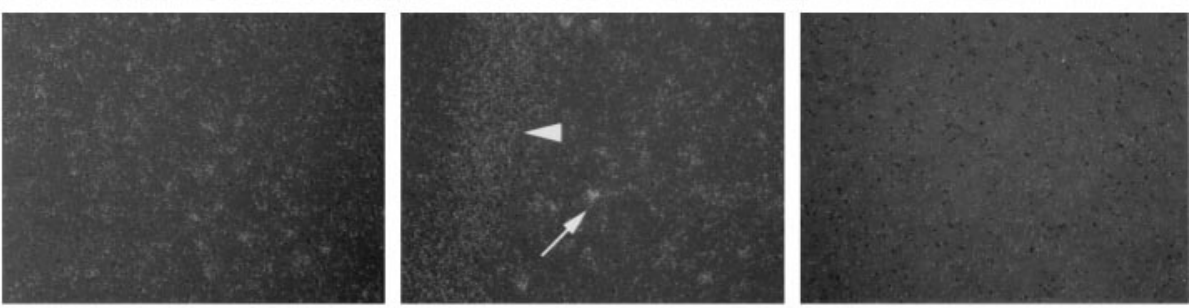

$\beta 1$
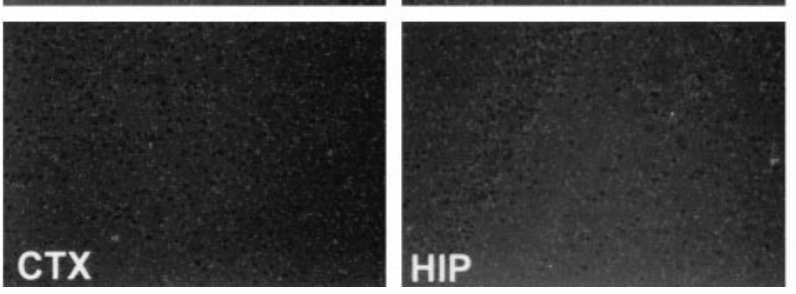

\section{RESULTS}

\section{Cloning and sequence analysis of human and mouse Slowpoke $\beta 4$}

To search for novel Slowpoke auxiliary subunits expressed in brain, we used a strategy of identifying brain proteins that are distantly related to the known $\beta$ subunits. A monkey striatal cDNA library was analyzed by high-throughput single-pass sequencing and automated BLAST searching of ESTs as described previously (Pan et al., 1997). A clone was identified on the basis of limited homology to the $\mathrm{N}$ terminus of the quail putative Slowpoke $\beta$ subunit (GenBank accession number U67865; blastp score, 70; $p=0.00011$; no blastn value). It also could be aligned with the $\mathbf{N}$ terminus of the human Slowpoke $\beta 1$ subunit $(\mathrm{h} \beta 1)$. The complete sequence of this clone was determined by primer walking and found to contain an open reading frame encoding a protein of 210 amino acids. A probe comprising the first 213 nucleotides of the open reading frame was used to screen a human fetal brain cDNA library, and several identical clones were obtained and sequenced. The open reading frame of these clones encodes a protein of 210 amino acids (Fig. 1a, top line), identical to the monkey protein. This protein exhibits only $20 \%$ amino acid identity with $\mathrm{h} \beta 1$ [in contrast, $\mathrm{h} \beta 1$ and $\mathrm{h} \beta 2 / 3$ are $43 \%$ identical (Wallner et al., 1999; Xia et al., 1999)] (Fig. 1a, bottom line), and so this novel Slowpoke auxiliary subunit is designated $h \beta 4 . h \beta 4$ is more closely related to $\mathrm{h} \beta 2 / 3$ (29\% identity), but it lacks the $\mathrm{N}$-terminal inactivating particle and does not confer inactivation on Slowpoke $\alpha$ subunits (see below).

A mouse homolog of $\mathrm{h} \beta 4$ was identified by BLAST search of the mouse EST database. The $\mathrm{m} \beta 4$ protein is $94 \%$ identical to $\mathrm{h} \beta 4$, with only a single nonconservative amino acid difference (Fig. 1a). The phylogenetic analysis in Figure $1 b$ emphasizes the distinction between the previously described Slowpoke $\beta$ subunits and mouse and human $\beta 4$. Like $\beta 1$ and $\beta 2 / 3$, the $\beta 4$ subunits contain two predicted membrane-spanning regions (Fig. 1a, horizontal lines), with a large extracellular loop between them containing conserved cysteine residues (Fig. 1a, arrows) and two putative sites for $\mathrm{N}$-linked glycosylation.

\section{Expression pattern of human Slowpoke $\beta 4$}

$\mathrm{h} \beta 4$ expression was first analyzed using multiple tissue Northern blots and brain region Northern blots (Fig. 2). $\mathrm{h} \beta 4$ is expressed predominantly in human brain (Fig. 2, top panels, lane 2), with a major mRNA product at $1.6 \mathrm{~kb}$ and a minor one at $5 \mathrm{~kb}$, whereas only limited expression is observed in non-neural tissues (lanes 1, 3-16). Indeed, no signal could be detected in sections of these non-neural tissues by in situ hybridization (see below). Within the brain regions analyzed, expression is highest in cortical regions (Fig. 2, bottom panels).

Tissue and regional expression of Slowpoke $\alpha$ and $\beta$ subunits was analyzed further in human and monkey by in situ hybridization. $\beta 4$ is expressed in all layers of human cortex (Fig. 3, left panel), and no signal is detected with a sense $(S)$ probe (Fig. 3, middle panel). At higher magnification (Fig. 3, right panel), hybridization can be seen predominantly over human cortical neurons. Film autoradiography of monkey brain sections (Fig. 4) demonstrates widespread expression of Slowpoke $\alpha$ subunit (Slo) and $\mathrm{h} \beta 4$ (top panels), particularly in cortex, basal ganglia, infundibulum, and hippocampus. Expression of $h \beta 2 / 3$ is less robust, 

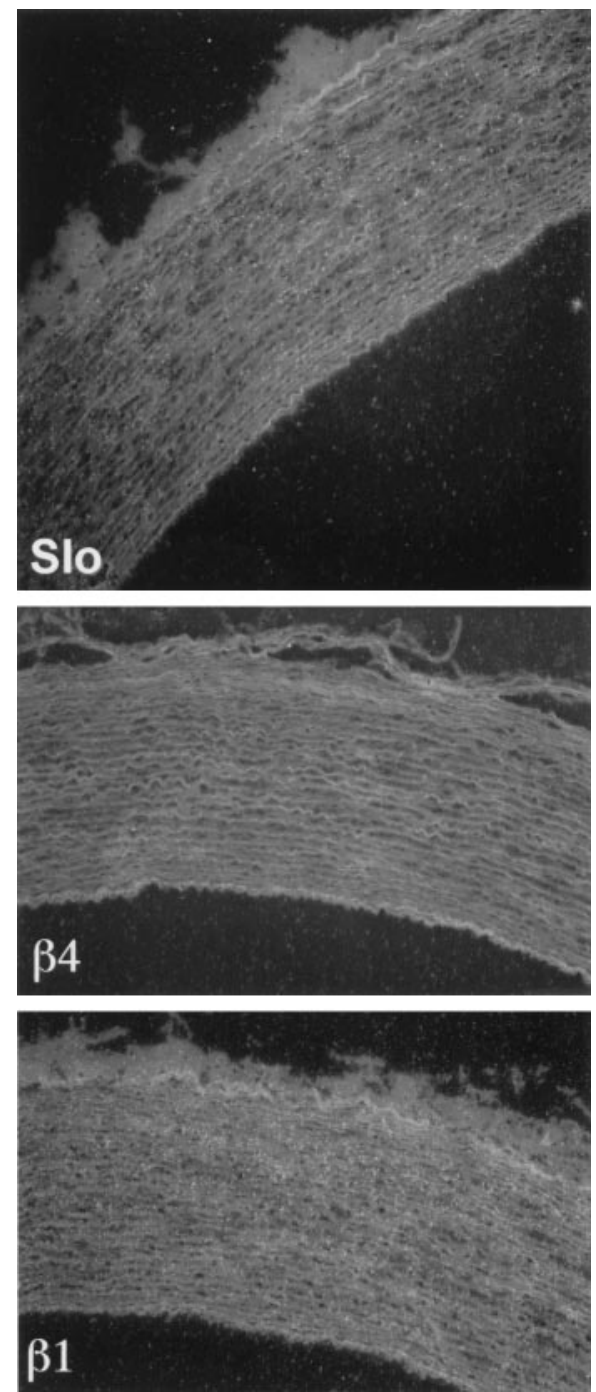

Figure 6. Analysis of Slowpoke $\alpha$ and $\beta$ subunit expression in monkey aorta. Emulsion autoradiograms of sections of monkey aorta labeled with antisense probes to Slowpoke $\alpha$ (Slo, top panel), $\beta 4$ (middle panel), and $\beta 1$ (bottom panel) subunits were viewed under dark-field illumination. Silver grains representing mRNA encoding $\alpha$ and $\beta 1$ subunits are readily visible over smooth muscle layers in the wall of the monkey aorta, whereas $\beta 4$ expression is not detectable ( $10 \times$ magnification).

and virtually no h $\beta 1$ mRNA can be detected (Fig. 4, bottom panels). It is also evident from emulsion autoradiography of monkey brain sections that there is a striking overlap in expression of Slowpoke $\alpha$ subunit (Fig. 5, top row) and h $\beta 4$ (Fig. 5, middle row) in multiple neuronal populations in cortex $(C T X)$, dentate gyrus, and CA3 regions of hippocampus (HIP) and thalamus (THL). The bottom two rows in Figure 5 confirm that there is more limited expression of $h \beta 2 / 3$ and no expression of $h \beta 1$ in these brain regions. $\beta 4$ expression is also detected in spinal motor neurons, sympathetic neurons of the superior cervical ganglion, and a subpopulation of dorsal root ganglion neurons (data not shown). This extensive brain distribution of $\beta 4$ may be contrasted with the situation in human aorta in which Slowpoke $\alpha$ subunit (Fig. 6, top panel) and $\mathrm{h} \beta 1$ (Fig. 6, bottom panel) are expressed prominently, but $\mathrm{h} \beta 4$ mRNA cannot be detected (Fig. 6, middle panel). In addition, despite the faint signal from these tissues on Northern blots, no $\beta 4$ expression is detected in sections of mon-

\section{Blot: Epitope-tagged $\beta 4$}

\section{a Human}

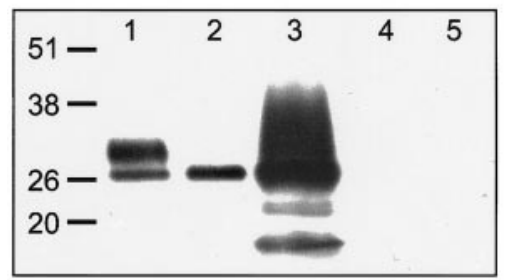

\section{b Mouse}

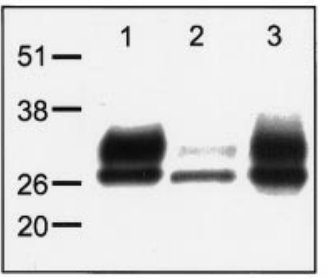

Figure 7. Mammalian Slowpoke $\alpha$ subunits coimmunoprecipitate with $\beta 4$ subunits. Shown are Western blots of cell lysates or IPs, using an antibody directed against the V5 epitope that detects V5-His tagged $\beta 4$ subunits. $a$, Human proteins. Lane 1, hSlo IP from cells transfected with hSlo and $\mathrm{h} \beta 4$; lane 2 , lysate from same cells as in lane 1 ; lane 3 , anti-His IP from same cells as in lane 1; lane 4, hSlo IP from cells transfected with hSlo alone; lane 5 , hSlo IP from cells transfected with $\mathrm{h} \beta 4$ alone. $b$, Mouse proteins. Lane 1, mSlo IP from cells transfected with $\mathrm{mSlo}$ and $\mathrm{m} \beta 4$; lane 2 , lysate from same cells as in lane 1; lane3, anti-His IP from same cells as in lane 1.

key heart, skeletal muscle, pancreas, liver, testes, lung, or adipose tissue by in situ hybridization (data not shown).

\section{Slowpoke $\beta 4$ binds to hSlo}

To determine whether $\beta 4$ is indeed a Slowpoke auxiliary subunit, we first asked whether it can coimmunoprecipitate with Slo. When HEK 293 cells are transfected with hSlo together with $\mathrm{h} \beta 4$ and hSlo is immunoprecipitated with a specific antibody, $\mathrm{h} \beta 4$ can be detected in the immunoprecipitate (Fig. 7a, lane 1). It is interesting that two coimmunoprecipitating protein bands are seen, one with an apparent molecular weight $(\sim 29 \mathrm{kDa})$ equivalent to that predicted for the epitope-tagged $\mathrm{h} \beta 4$, and the second several kilodaltons larger (lane 1). Although the higher molecular weight band is barely detectable in the cell lysate (lane 2) and in a $\mathrm{h} \beta 4$ immunoprecipitate (lane 3), it clearly is enriched relative to the smaller band in the hSlo immunoprecipitate (lane 1). No $\mathrm{h} \beta 4$ staining is observed in hSlo immunoprecipitates from cells in which either hSlo (lane 4 ) or $\mathrm{h} \beta 4$ (lane 5) is transfected alone. A similar result is observed when the interaction between mSlo and $\mathrm{m} \beta 4$ is analyzed (Fig. $7 b$ ). In this case, the higher molecular weight $\mathrm{m} \beta 4$ band is more evident in the lysate (lane 2 ) and $\mathrm{m} \beta 4$ immunoprecipitate (lane 3), but it too preferentially coimmunoprecipitates with mSlo (lane 1). These results suggest that $\mathrm{h} \beta 4$ and $\mathrm{m} \beta 4$ may exist in several different post-translationally modified forms, one of which binds preferentially to Slowpoke $\alpha$ subunits. Slowpoke- $\beta 4$ binding is also observed when the experiment is done by immunoprecipitating epitope-tagged $\beta 4$ and probing for Slowpoke $\alpha$ subunit with anti-Slowpoke antibodies (data not shown).

\section{Slowpoke $\beta 4$ modulates hSlo activation kinetics}

hSlo current was measured in inside-out membrane patches from HEK 293 cells transfected with hSlo $\alpha$ subunit. As shown in 
a

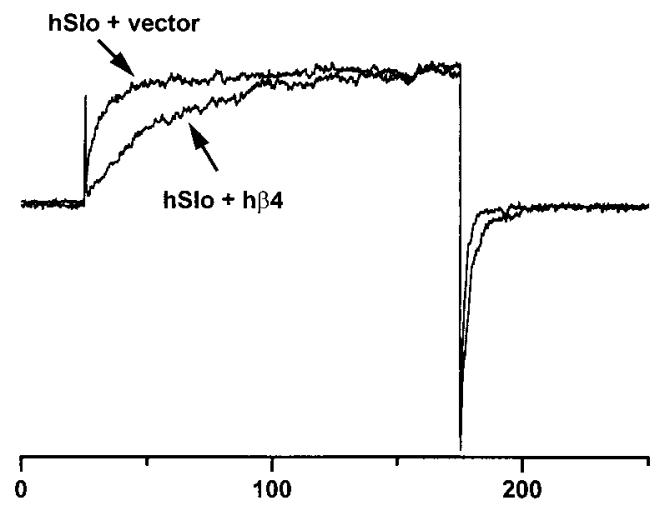

b

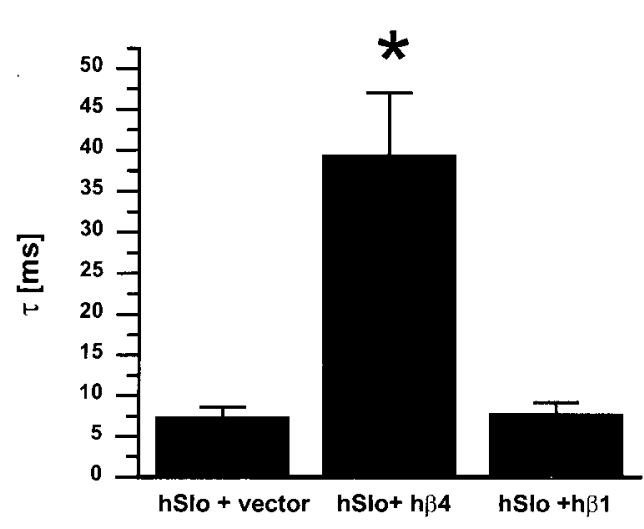

C

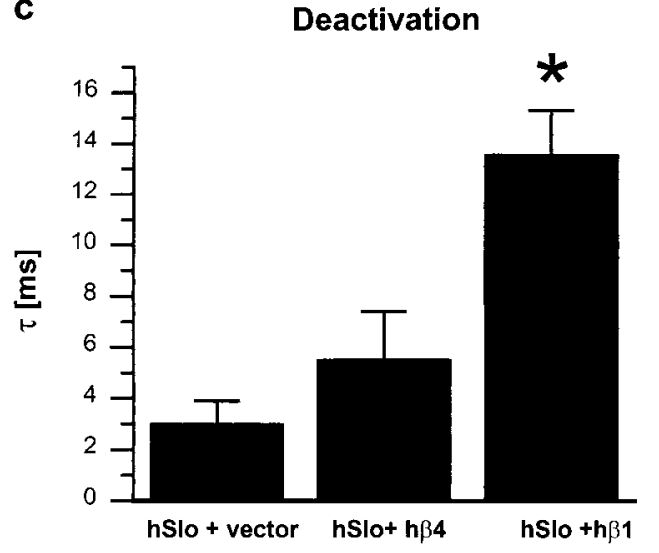

Figure 8. $\mathrm{h} \beta 4$ decreases Slowpoke activation rate but does not affect its deactivation rate. $a$, Normalized currents recorded at $+80 \mathrm{mV}$ from cells transfected with either hSlo and control vector, or hSlo and h $\beta 4 . b$ and $c$ show time constants $(\tau)$ calculated from single exponential fits of current traces. $b$, Activation kinetics: $\mathrm{h} \beta 4$ increases the activation time constant significantly $(p<0.001)$, whereas $\mathrm{h} \beta 1$ is without effect $(p>0.05) . c$, Deactivation kinetics: $\mathrm{h} \beta 4$ does not alter the deactivation time constant $(p>0.05)$, whereas $\mathrm{h} \beta 1$ increases it significantly $(p<0.001)$. Recording conditions: detached inside-out patches, symmetrical $\mathrm{K}^{+}$solutions, $1 \mu \mathrm{M}$ free $\mathrm{Ca}^{2+}$ on the intracellular side, holding potential of $-100 \mathrm{mV}$, steps to $+80 \mathrm{mV}$. a

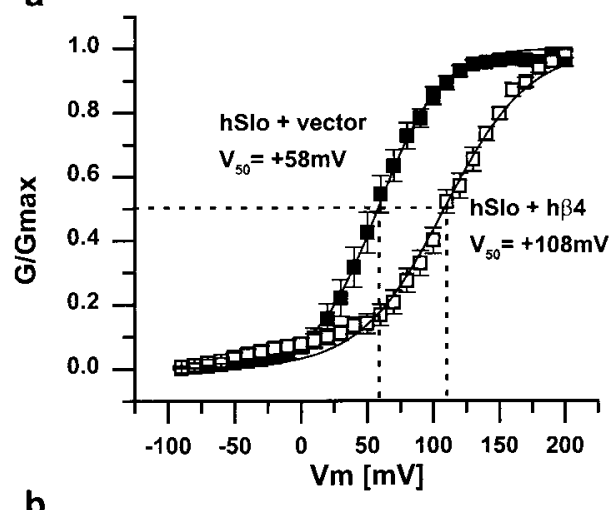

b

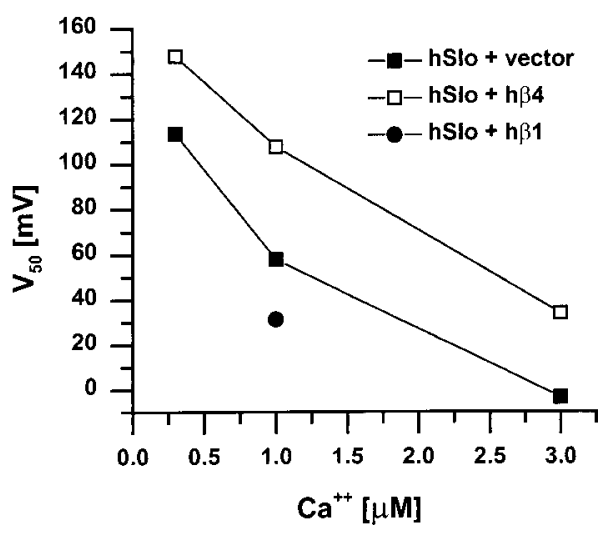

Figure 9. Steady-state activation of hSlo in the presence or absence of $\mathrm{h} \beta 1$ or $\mathrm{h} \beta 4 . a, \mathrm{~h} \beta 4$ shifts the steady-state activation curve to the right, indicating that more depolarized voltages are required to open the channel. $V_{50}$ (indicated by the dotted lines) is the half maximal activation voltage for each condition. Holding potential of $-100 \mathrm{mV}, 1 \mu \mathrm{M}$ free calcium on the intracellular side, data fitted to the Boltzmann equation ( $n=11$ for hSlo plus vector; $n=10$ for hSlo plus $\mathrm{h} \beta 4$ ). $b, V_{50}$ is shifted in the depolarizing direction by $\mathrm{h} \beta 4$ at all calcium concentrations tested. In contrast, $\mathrm{h} \beta 1$ shifts the half-maximal activation voltage in the hyperpolarizing direction.

Figure $8 a$, activation of the current in response to a depolarizing voltage step to $+80 \mathrm{mV}$ is much slower in cells cotransfected with $\mathrm{h} \beta 4$. The time constant $(\tau)$ for activation of hSlo current is $7.4 \pm$ $1.2 \mathrm{msec}(n=9)$ in the absence and $39 \pm 7.5 \mathrm{msec}(n=5)$ in the presence of $\mathrm{h} \beta 4$ (Fig. $8 b$ ). A similar slowing of activation was observed at all other voltages examined between +70 and +120 $\mathrm{mV}$ (data not shown). This may be contrasted with $\mathrm{h} \beta 1$, which does not influence the time course of activation $(\tau$ of $7.8 \pm 1.4$ msec, $n=4$ ) (Fig. $8 b$ ). A different pattern is observed when hSlo deactivation is considered. As is evident from inspection of the current traces in Figure $8 a, \mathrm{~h} \beta 4$ has little or no effect on the deactivation kinetics, and this is confirmed by the deactivation $\tau$ values in Figure $8 c(\tau$ of $3.0 \pm 0.9 \mathrm{msec}, n=9$ in the absence of $\mathrm{h} \beta 4 ; \tau$ of $5.5 \pm 1.9 \mathrm{msec}, n=5$ in the presence of $\mathrm{h} \beta 4)$. Again this may be contrasted with $\mathrm{h} \beta 1$ which, as shown previously (Dworetzky et al., 1996; Tseng-Crank et al., 1996), slows deactivation ( $\tau$ of $14 \pm 1.7 \mathrm{msec}, n=4$ ) (Fig. $8 c$ ).

\section{Slowpoke $\beta 4$ modulates the voltage dependence of hSlo activation}

$\mathrm{h} \beta 4$ can also influence the steady-state activation of hSlo. In cells cotransfected with $\mathrm{h} \beta 4$, the voltage dependence of hSlo activation 
a

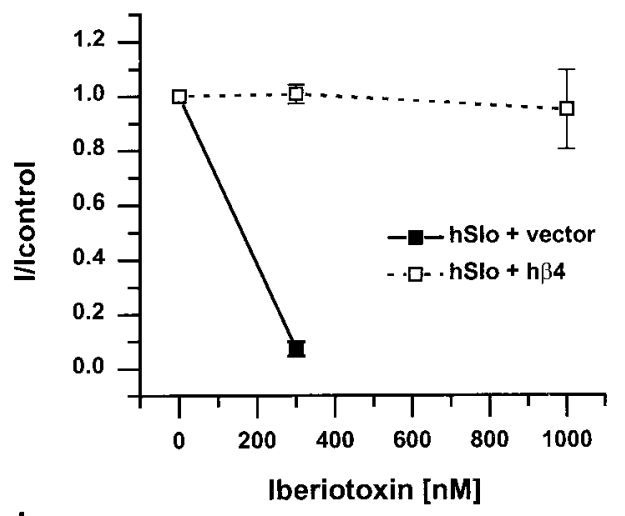

b

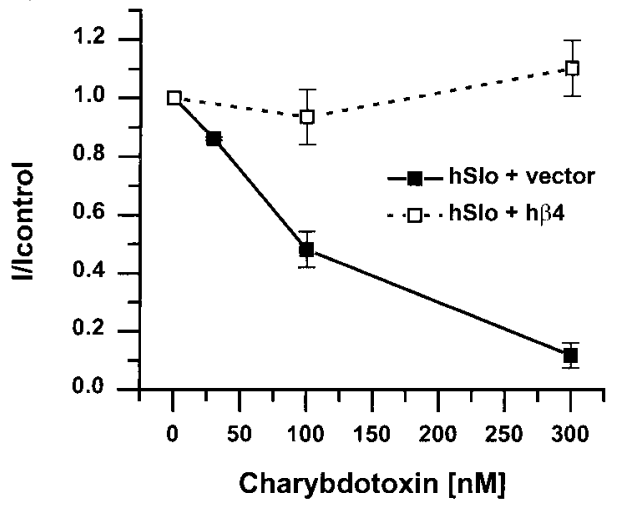

Figure 10. $\mathrm{h} \beta 4$ protects hSlo from block by iberiotoxin $(a)$ and charybdotoxin $(b)$. Experiments were done in the whole-cell patch-clamp mode, and toxins were applied from the extracellular side. hSlo currents recorded in the presence of different concentrations of toxins were normalized to the control current in the absence of toxin. The filled symbols with solid lines show the block of current by toxins in the absence of $\mathrm{h} \beta 4$, and the open symbols with dashed lines show that current is not blocked, even by high concentrations of toxin, in the presence of $\mathrm{h} \beta 4(n=3$; holding potential of $-85 \mathrm{mV}$, steps to $+105 \mathrm{mV}, 10 \mu \mathrm{M}$ free internal calcium). Note the different concentration axes in $a$ and $b$.

is shifted some $50 \mathrm{mV}$ to the right compared with cells transfected with hSlo alone (Fig. 9a). This requirement for greater depolarization to activate the current is apparent at all calcium concentrations examined in the range from 0.3 to $3 \mu \mathrm{M}$ (Fig. $9 b$ ). In marked contrast, as shown previously by many workers (McManus et al., 1995; Dworetzky et al., 1996; Tseng-Crank et al., 1996; Wallner et al., 1996; Xia et al., 1999), h $\beta 1$ shifts the voltage required for half-maximal activation by $20-50 \mathrm{mV}$ in the opposite direction (Fig. 9b). A similar result has been reported for $\mathrm{h} \beta 2 / 3$ (Wallner et al., 1999; Xia et al., 1999).

\section{Slowpoke $\beta 4$ modulates toxin block of hSlo}

Because auxiliary subunits often alter the effects of pharmacological agents on Slowpoke channel $\alpha$ subunits, we tested the effects of $\mathrm{h} \beta 4$ on the block of hSlo current by the scorpion venom toxins charybdotoxin and iberiotoxin, in the whole-cell patch recording configuration. As shown in Figure 10, $a$ and $b$, in cells transfected with hSlo and control vector, the current is blocked $90 \%$ or more by $300 \mathrm{~nm}$ of either toxin (filled symbols). In the presence of $\mathrm{h} \beta 4$, in contrast, no block at all is observed by $300 \mathrm{~nm}$ toxin (Fig. 10a,b, open symbols), and even as much as $1 \mu \mathrm{M}$ iberiotoxin is without effect (Fig. 10a). h $\beta 1$ (Dworetzky et al., 1996; Zhou et al., 1998) and $\mathrm{h} \beta 2 / 3$ (Xia et al., 1999) also decrease channel sensitivity to toxins but to a much smaller extent.

\section{DISCUSSION}

The pattern of neuronal electrical activity can vary widely from one neuron to another. Much of this diversity in electrical activity arises from differences in potassium channel activity in different cells. A large number of genes that encode potassium channels have been identified (Jan and Jan, 1997), and some of these are subject to extensive alternative splicing that can generate even greater diversity (Schwarz et al., 1988; Adelman et al., 1992; Tseng-Crank et al., 1994). Yet another mechanism that is a major contributor to functional diversity is the interaction of the poreforming $\alpha$ subunits of potassium channels and other channels with a wide variety of auxiliary proteins that can influence channel expression, membrane localization, and gating properties (Isom et al., 1994; Rhodes et al., 1995; Trimmer, 1998).

We describe here human and mouse genes for a novel auxiliary subunit of the Slowpoke family of large conductance $\mathrm{K}_{\mathrm{Ca}}$ channels. This protein, which we call Slowpoke $\beta 4$, was originally identified as a candidate Slowpoke auxiliary subunit on the basis of its amino acid sequence homology with a known Slowpoke $\beta$ subunit. Although the predicted membrane topology of $\beta 4$ is similar to that of $\beta 1$ and $\beta 2 / 3$, the sequence homology in fact is very limited. In addition, $\beta 4$ exhibits a unique tissue distribution and modulates Slowpoke channel activity very differently from the Slowpoke $\beta$ subunits that have been described previously. $\beta 4$ is also distinct from the several Slowpoke-interacting proteins that have been identified recently by yeast two-hybrid screens (Schopperle et al., 1998; Xia et al., 1998; Zhou et al., 1999). Particularly noteworthy is our finding that $\mathrm{h} \beta 4$ is unique among Slowpoke $\beta$ subunits in that it is expressed predominantly in the brain and peripheral nervous system. Northern blots show predominant expression in brain, especially cortical regions, and this is readily confirmed by in situ hybridization. Although there is a weak signal from several non-neural peripheral tissues on Northern blots, we could not detect expression of $\beta 4$ in these tissues by in situ hybridization. The most striking result of these localization experiments is that the expression of $\beta 4$ in brain and peripheral sensory neurons overlaps with that of Slowpoke $\alpha$ subunit, suggesting that $\beta 4$ is available to interact with and modulate Slowpoke in most neurons. Recent protein purification experiments have identified a Slowpoke-binding protein in rat brain that is immunologically distinct from and smaller than the smooth muscle $\beta 1$ subunit (Wanner et al., 1999). It will be of interest to determine whether this copurifying protein is related to Slowpoke $\beta 4$.

The actions of $\mathrm{h} \beta 4$ on hSlo channel activity are also unique. The two major modulatory effects we have observed, a slowing of activation kinetics and a shift of the voltage dependence of activation to more depolarized voltages, will combine to produce a marked downregulation of channel activity. This may be contrasted with the $\beta 1$ subunit, which shifts the voltage dependence of the channel to more hyperpolarized voltages and slows deactivation, thereby increasing channel activity. The net effect of $\mathrm{h} \beta 2 / 3$ is harder to assess, because it both shifts the voltage dependence to more hyperpolarized voltages and also causes channel inactivation (Wallner et al., 1999; Xia et al., 1999). Nevertheless, it can be predicted with confidence that $\beta 1, \beta 2 / 3$, and $\beta 4$ will have very different effects on the excitability of the cells in which they are expressed. For example, neurons that express $\mathrm{h} \beta 4$ in their axons and nerve terminals are likely to be more excitable, and release of neurotransmitter is likely to be 
prolonged compared with those that express $\beta 1$ or no auxiliary subunit at all. It is also conceivable that auxiliary subunit binding is not constitutive, but itself is regulated by signals that impinge on a neuron, thereby allowing a rapid and dramatic shift in neuronal electrical properties (for an example of this, see Zhou et al., 1999). This idea is especially intriguing in the case of $\beta 4$ because of our finding that it can exist in cells in at least two distinct forms, one of which binds preferentially to Slowpoke $\alpha$ subunit. It will be important to determine whether such dynamically regulated interactions of auxiliary subunits with ion channels contribute to neuronal plasticity in the mammalian brain and whether these interactions are perturbed in disease states or other pathological situations.

\section{REFERENCES}

Adelman JP, Shen K-Z, Kavanaugh MP, Warren RA, Wu Y-N, Lagrutta A, Bond CT, North RA (1992) Calcium- activated potassium channels expressed from cloned complementary DNAs. Neuron 9:209-216.

Bielefeldt K, Jackson MB (1994) Phosphorylation and dephosphorylation modulate a $\mathrm{Ca}^{2+}$-activated $\mathrm{K}^{+}$channel in rat peptidergic nerve terminals. J Physiol (Lond) 475:241-254.

Butler A, Tsunoda S, McCobb DP, Wei A, Salkoff L (1993) mSlo, a complex mouse gene encoding "maxi" calcium-activated potassium channels. Science 261:221-224.

Dunlap K, Luebke JI, Turner TJ (1995) Exocytotic $\mathrm{Ca}^{2+}$ channels in mammalian central neurons. Trends Neurosci 18:89-98.

Dworetzky SI, Trojnacki JT, Gribkoff VK (1994) Cloning and expression of a human large-conductance calcium-activated potassium channel. Mol Brain Res 27:189-193.

Dworetzky SI, Boissard CG, Lum-Ragan JT, McKay MC, Post-Munson DJ, Trojnacki JT, Chang C-P, Gribkoff VK (1996) Phenotypic alteration of a human BK (hSlo) channel by hSlob subunit coexpression: changes in blocker sensitivity, activation/relaxation and inactivation kinetics, and protein kinase A modulation. J Neurosci 16:4543-4550.

Garcia-Calvo M, Knaus H-G, McManus OB, Giangiacomo KM, Kaczorowski GJ, Garcia ML (1994) Purification and reconstitution of the high-conductance, calcium-activated potassium channel from tracheal smooth muscle. J Biol Chem 269:676-682.

Gho M, Ganetzky B (1992) Analysis of repolarization of presynaptic motor terminals in Drosophila larvae using potassium channel-blocking drugs and mutations. J Exp Biol 170:93-111.

Hanner M, Vianna-Jorge R, Kamassah A, Schmalhofer WA, Knaus H-G, Kaczorowski GJ, Garcia ML (1998) The $\beta$ subunit of the high conductance calcium-activated potassium channel. J Biol Chem 273:16289-16296.

Hicks GA, Marrion NV (1998) $\mathrm{Ca}^{2+}$-dependent inactivation of large conductance $\mathrm{Ca}^{2+}$-activated $\mathrm{K}^{+}$(BK) channels in rat hippocampal neurones produced by pore block from an associated particle. J Physiol (Lond) 508:721-734.

Isom LL, De Jongh KS, Catterall WA (1994) Auxiliary subunits of voltage-gated ion channels. Neuron 12:1183-1194.

Jan LY, Jan YN (1997) Voltage-gated and inwardly rectifying potassium channels. J Physiol (Lond) 505:267-282.

Kaczorowski GJ, Knaus HG, Leonard RJ, McManus OB, Garcia ML (1996) High-conductance calcium-activated potassium channels; structure, pharmacology, and function. J Bioenerg Biomembr 28:255-267.

Knaus HG, Folander K, Garcia-Calvo M, Garcia ML, Kaczorowski GJ, Smith M, Swanson R (1994) Primary sequence and immunological characterization of beta-subunit of high conductance $\mathrm{Ca}(2+)$-activated $\mathrm{K}^{+}$channel from smooth muscle. J Biol Chem 269:17274-17278.

Knaus H-G, Schwarzer C, Koch ROA, Eberhart A, Kaczorowski GJ, Glossmann H, Wunder F, Pongs O, Garcia ML, Sperk G (1996) Distribution of high-conductance $\mathrm{Ca}^{2+}$-activated $\mathrm{K}^{+}$channels in rat brain: targeting to axons and nerve terminals. J Neurosci 16:955-963.

McManus OB, Helms LMH, Pallanck L, Ganetzky B, Swanson R, Leonard RJ (1995) Functional role of the $\beta$ subunit of high conductance calcium-activated potassium channels. Neuron 14:645-650.

Oberst C, Weiskirchen R, Hartl M, Bister K (1997) Suppression in transformed avian fibroblasts of a gene (CO6) encoding a membrane protein related to mammalian potassium channel regulatory subunits. Oncogene 14:1109-1116.

Pallanck L, Ganetzky B (1994) Cloning and characterization of human and mouse homologs of the Drosophila calcium-activated potassium channel gene, slowpoke. Hum Mol Genet 3:1239-1243.

Pan Y, Lloyd C, Zhou H, Dolich S, Deeds J, Gonzalo JA, Vath J, Gosselin M, Ma J, Dussault B, Woolf E, Alperin G, Culpepper J, GutierrezRamos JC, Gearing D (1997) Neurotactin, a membrane-anchored chemokine upregulated in brain inflammation. Nature 387:611-617.

Rettig J, Heinemann SH, Wunder G, Lorra C, Parcej DN, Dolly JO, Pongs O (1994) Inactivation properties of voltage-gated $\mathrm{K}^{+}$channels altered by presence of $\beta$-subunit. Nature 369:289-294.

Rhodes KJ, Keilbaugh SA, Barrezueta NX, Lopez KL, Trimmer JS (1995) Association and colocalization of $\mathrm{K}^{+}$channel $\alpha$ - and $\beta$-subunit polypeptides in rat brain. J Neurosci 15:5360-5371.

Robitaille R, Charlton MP (1992) Presynaptic calcium signals and transmitter release are modulated by calcium-activated potassium channels. J Neurosci 12:297-305.

Robitaille R, Garcia ML, Kaczorowski GJ, Charlton MP (1993) Functional colocalization of calcium and calcium-gated potassium channels in control of transmitter release. Neuron 11:645-655.

Schopperle WM, Holmqvist MH, Zhou Y, Wang J, Wang Z, Griffith LC, Keselman I, Kusinitz F, Dagan D, Levitan IB (1998) Slob, a novel protein that interacts with the slowpoke calcium-dependent potassium channel. Neuron 20:565-573.

Schwarz TL, Tempel BL, Papazian DM, Jan YN, Jan LY (1988) Multiple potassium-channel components are produced by alternative splicing at the Shaker locus in Drosophila. Nature 331:137-142.

Solaro CR, Lingle CJ (1992) Trypsin-sensitive, rapid inactivation of a calcium-activated potassium channel. Science 257:1694-1698.

Solaro CR, Prakriya M, Ding JP, Lingle CJ (1995) Inactivating and noninactivating $\mathrm{Ca}^{2+}$ - and voltage-dependent $\mathrm{K}^{+}$current in rat adrenal chromaffin cells. J Neurosci 15:6110-6123.

Stahl A, Hirsch DJ, Gimeno RE, Punreddy S, Ge P, Watson N, Patel S, Kotler M, Raimondi A, Tartaglia L, Lodish HF (1999) Identification of the major intestinal fatty acid transport protein. Mol Cell 4:299-308.

Trimmer JS (1998) Regulation of ion channel expression by cytoplasmic subunits. Curr Opin Neurobiol 8:370-374.

Tseng-Crank J, Foster CD, Krause JD, Mertz R, Godinot N, DiChiara TJ, Reinhart PH (1994) Cloning, expression, and distribution of functionally distinct $\mathrm{Ca}^{2+}$-activated $\mathrm{K}^{+}$channel isoforms from human brain. Neuron 13:1315-1330.

Tseng-Crank J, Godinot N, Johansen TE, Ahring PK, Strobæk D, Mertz R, Foster CD, Olesen S-P, Reinhart PH (1996) Cloning, expression, and distribution of a $\mathrm{Ca}^{2+}$-activated $\mathrm{K}^{+}$channel $\beta$-subunit from human brain. Proc Natl Acad Sci USA 93:9200-9205.

Valverde MA, Rojas P, Amigo J, Cosmelli D, Orio P, Bahamonde MI, Mann GE, Vergara C, Latorre R (1999) Acute activation of Maxi-K channels (hSlo) by estradiol binding to the beta subunit. Science 285:1929-1931.

Vergara C, Latorre R, Marrion NV, Adelman JP (1998) Calciumactivated potassium channels. Curr Opin Neurobiol 8:321-329.

Wallner M, Meera P, Toro L (1996) Determinant for $\beta$-subunit regulation in high-conductance voltage-activated and $\mathrm{Ca}^{2+}$-sensitive $\mathrm{K}^{+}$ channels: an additional transmembrane region at the $\mathrm{N}$ terminus. Proc Natl Acad Sci USA 93:14922-14927.

Wallner M, Meera P, Toro L (1999) Molecular basis of fast inactivation in voltage and $\mathrm{Ca}^{2+}$-activated $\mathrm{K}^{+}$channels: a transmembrane $\beta$-subunit homolog. Proc Natl Acad Sci USA 96:4137-4142.

Wanner SG, Koch RO, Koschak A, Trieb M, Garcia ML, Kaczorowski GJ, Knaus HG (1999) High-conductance calcium-activated potassium channels in rat brain: pharmacology, distribution, and subunit composition. Biochemistry 38:5392-5400.

Xia X-M, Hirschberg B, Smolik S, Forte M, Adelman JP (1998) dSlo interacting protein 1 , a novel protein that interacts with largeconductance calcium-activated potassium channels. J Neurosci 18:2360-2369.

Xia X-M, Ding JP, Lingle CJ (1999) Molecular basis for the inactivation of $\mathrm{Ca}^{2+}$ - and voltage-dependent BK channels in adrenal chromaffin cells and rat insulinoma tumor cells. J Neurosci 19:5255-5264.

Zhou XB, Schlossmann J, Hofmann F, Ruth P, Korth M (1998) Regulation of stably expressed and native BK channels from human myometrium by cGMP- and cAMP-dependent protein kinase. Pflügers Arch 436:725-734.

Zhou Y, Schopperle W M, Murrey H, Jaramillo H, Dagan D, Griffith LC, Levitan IB (1999) A dynamically regulated 14-3-3, Slob, and Slowpoke potassium channel complex in Drosophila presynaptic nerve terminals. Neuron 22:809-818. 